\title{
An interesting case of Wide QRS tachycardia. What is the mechanism?
}

Krishna Kumar Mohanan Nair ${ }^{1}$, Narayanan Namboodiri² ${ }^{2}$, and Ajitkumar Valaparambil ${ }^{2}$

${ }^{1}$ SCTIMST

${ }^{2}$ Sree Chitra Tirunal Institute for Medical Sciences and Technology

July 25, 2020

\section{Hosted file}

MANUSCRIPT JCE.doc available at https://authorea.com/users/318868/articles/472253-aninteresting-case-of-wide-qrs-tachycardia-what-is-the-mechanism

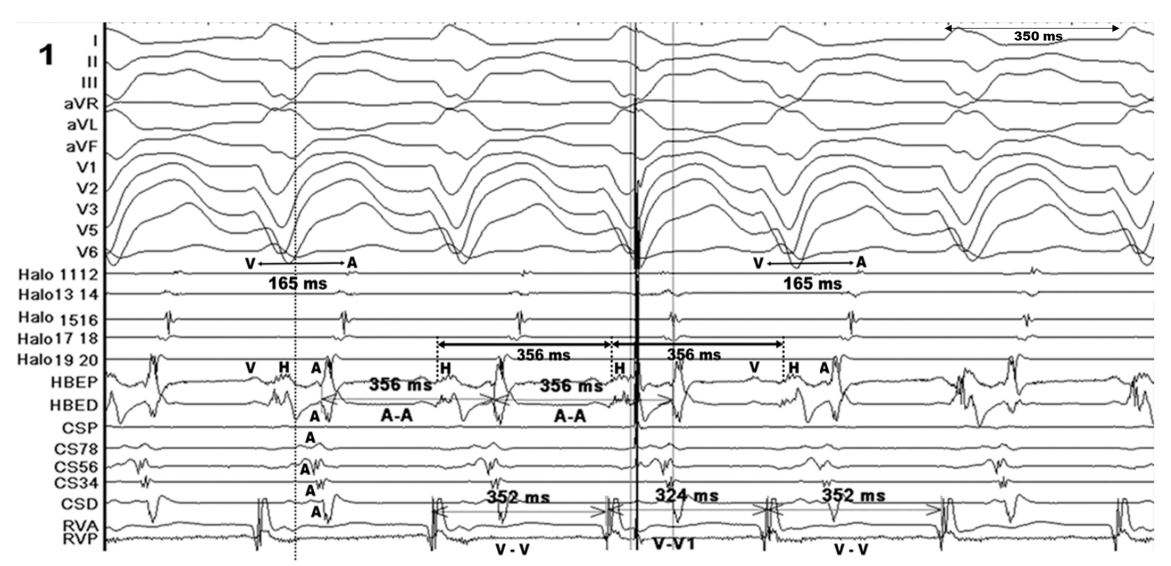

